\title{
Vegetative Propagation of Peltophorum Petrocarpum (DC.) Backer ex K.Heyne a Multipurpose Tree
}

\author{
Fadwa Mohammed Ahmed Ali ${ }^{1}$, Yahia Hamid Ali Elbasheer ${ }^{2}$ \\ ${ }^{1}$ Forest Silviculture and Tissue Culture, Agriculture Research Corporation, Forestry Research Centre, Khartoum, SUDAN \\ ${ }^{2}$ Horticulture, Shambat Research Station, Agriculture Research Corporation, Forestry Research Centre, Khartoum, \\ SUDAN
}

\begin{abstract}
This paper describes a successful protocol of vegetative propagation by using stem cuttings of mature Peltophorum petrocarpum plants. The experiment was conducted in the nursery of the Forestry Research Centre at Soba during November 2011and April 2012. The socioeconomic importance of P. petrocarpum comes from its multipurpose uses and there is a demand in production of its seed for tree planting and domestication activities. Hence there is a need for efficient and economically feasible propagation method of P. pterocarpum. Therefore the objective of study is to develop a vegetative propagation protocol by using rooted stem cuttings; and to determine the effects of the rooting hormone indole-3-butyric acid (IBA) on rooting potentiality of stem cuttings of mature mother plants. The result revealed a significant effect $(\mathrm{p}<0.001)$ of IBA concentrations on rooting percentage and growth performance of stem cuttings. The highest rooting percent was obtained with 200ppm IBA which was not significantly different from 100ppm, but significantly different from 50 and $0.0 \mathrm{ppm}$. The effect of IBA concentrations on root lengths and of roots per cutting was significantly different from 0.0 and 50ppm treatments. Although 100ppm IBA gave the tallest root $(4.6 \mathrm{~cm})$ but it was not significantly different from 200ppm $(4.3 \mathrm{~cm})$. Survival of rooted cuttings after transplanting from the propagator was $100 \%$ and $97 \%$ with 100 and 200mg IBA respectively. Accordingly the conclusion reached is that rooted cuttings can be used successfully for obtaining health, uniform plantations of $P$. petrocarpum for largescale, biomass production and tree planting programmes.
\end{abstract}

Key words: vegetative propagation; rooted stem cuttings, rooting hormones

How to Cite: Ali FM and Elbasheer YH. 2014. Vegetative Propagation of Peltophorum petrocarpum (DC.) Backer ex K.Heyne a Multipurpose Tree Malaysian Journal of Medical and Biological Research, 1, 79-84.

This article is is licensed under a Creative Commons Attribution-NonCommercial 4.0 International License.

Attribution-NonCommercial (CC BY-NC) license lets others remix, tweak, and build upon work non-commercially,

and although the new works must also acknowledge \& be non-commercial.

\section{INTRODUCTION}

Forest tree species are known to have long life cycles and often display changes with time in growth rate and morphological feature that are reflected in growth characteristics such as, stem form, volume and yield. It has been reported that maturation-related changes in 
performance are developmental changes triggered by programmed activation or inactivation of different sets of genes (Libby and Rauter, 1984). Every tree offers a variety of clues to be identified; its tree's form, leaves, bark, buds and twigs, flower, fruit, and site or cultural requirements are characteristics unique to a species, variety, and cultivar.

$P$. pterocarpurum tree belongs to the family Fabaceae and tribe Caesalpiniaceae, has a wide distribution in tropical South East Asia and northern Australia and Africa. It is a small to medium sized tree reaches a height of 15 to $25 \mathrm{~m}$; its crown is domed shaped with ample shade. Inflorescences panicles, flowers are bright yellow forming an attractive element, fruiting during February and March, 1-3 seeded coppers' brown (El Amin, 1990). The roots are growing deep in soil and are seldom destructive to pavements that make it a favorite ornamental and shade tree. P. pterocarpum is fairly wind-firm, not attacked by boring beetles and becomes a common wayside tree, planted extensively inland to adorn gardens, parks, roadsides and agroforestry farms (Wee, 2003). Nevertheless its socioeconomic importance is associated with its multipurpose uses; such as planting for bee-keeping; and as fodder crop. The bark produces yellow-brown dye, used as colouration agent. The wood is durable and used for furniture as well as its wide uses in traditional medicine. It is known to possess antibacterial and antifungal properties. The bark extracts are believed to be effective in curing dysentery and relieving ulcers, muscular pain and sprains. The extracts can also be used as an eye lotion, gargle and even as tooth powder (Koh, et al, 2009).

Vegetative propagation technologies were well documented and published and have been successfully practiced for decades specifically by horticulturalists. The common modes are stem cuttings, layering, grafting and recently cell tissue and organ culture (Hartman and Kester, 1983; Longman and Jenik, 1990). In forest tree improvement and tree plantations recently the applications are concentrated on stem cutting and grafting, but various layering, hedging and pruning techniques were developed to rejuvenate old tree materials to root. However vegetative propagation permits the use of specific combining abilities in tree improvement and producing planting stocks identical to parent. Rooted cuttings in tree improvement programme were preferred than other methods (Ahlawat et al., 2003). Other benefits are preservation of genotypes by using clone banks, multiplication of desired genotypes to be used in seed or breeding orchards; evaluation of genotypes $\times$ environment interaction through clone testing in operational programmes. The success of rooting of cuttings was reported to be more or less affected by a number of factors such as, age, early selection of desired characters and interaction with the environment (Leakey et al., 1990; Ali and El-Tigani, 2003). In hard wood or difficult to root stem cuttings, auxins and cytokinins levels are reported to be inversely correlated in vivo and high auxins treatment can inhibit cytokinins biosynthesis (Eklöf et al., 2000 and Nordström et al., 2004).

Work on cuttings of fruit trees and of some forest trees showed that; the degree of lignifications in the primary phloem affects rooting ability of cuttings from trees by hindering root primordia tissue to develop root initials (Ali, 1986; El-Tigani 2003). Depending on the current successes it was suggested that; it is the time to propose cloning forestry as an alternative propagation methods comparable to conventional seedling-based forestry (Hussey, 1986; Longman and Jenik, 1990; Ali and El-Tigani, 2003). The achieves attained in rooting of mature trees cuttings showed a considerable improvement over the previous work (Ali, 1986; Badj, et al., 1991).

Generally; vegetative propagation of trees is viewed as an alternative way of raising plant stock. However as regard to P. pterocarpum, it is commonly propagated by seeds but the fact that; the seeds produced are few compared to quantity of required seeds and; sometimes are not available for planting purposes due to difficulties in seed collection, and to insects attack,. Accordingly there is a need for economically feasible propagation method, for tree planting and domestication activities. Therefore the general objective of 
study is to develop a vegetative propagation protocol; and the specific objectives of the study are; to explore the possibility of propagating mature $P$. petrocarpum tree by stem cuttings and to determine the best concentration of the hormone indole 3-butyric acid (IBA) on rooting potentiality of stem cuttings obtained from mature mother plants.

\section{Materials and Methods}

The experiment was conducted in the nursery of the Forestry Research Centre at Soba (Lat. $12^{\circ} \mathrm{N}$ and Log. $24^{\circ} \mathrm{E}$ ), during the period November 2011 and April 2012. The experiment was carried out in a glass covered propagator placed under a lath house made of bamboo and $70 \%$ shaded polythene net to create optimum rooting conditions. The rooting medium used was pure coarse sand.

Preparation of cutting materials: The stem cuttings were obtained from mature mother trees at Forestry Research Centre yard. Mother trees were selected on the basis of their uniformity in growth habits. Mixed stem cuttings $15-20 \mathrm{~cm}$ lengths and $0.5-1.5 \mathrm{~cm}$ in diameters were taken early in morning from mature branches after removal of leaves except 2-3 pairs, slant upper cut was made few centimeters above the upper node, and a horizontal lower cut was made below the basal node.

Application of growth hormone: The treatments performed included applications of the growth regulator indole-3-butyric acid (IBA ) in a solution form at concentrations of 0, 50, 100 and $200 \mathrm{ppm}$. IBA solutions were prepared according to the dilute-solution-dip method (Hartmann and Kester, 1983; Ali, 2007) using 70\% ethanol as a solvent. The base of the cutting was dipped in the specified IBA solution concentration for $18 \mathrm{~h}$; thereafter the cuttings were washed under running tap water, dried and planted in moist sand rooting medium and placed inside the nursery propagator. The medium was kept moist by frequent watering using hand water can sprayer to provide a humid environment. During the experiment humidity was kept in the range of 80 to $100 \%$ and the temperature 18 to $23^{\circ} \mathrm{C}$ during morning or 28 to $35^{\circ} \mathrm{C}$ after mid-day. The glass cover was removed for about 1 to $2 \mathrm{~h}$ every day in early morning for ventilation and illumination was the natural diffused day-light.

Experimental design and analysis: The set of the experiment was arranged in a complete randamized design with three replicates with four treatments, the control and three levels of hormone concentration; and each plot cosisted of 15 cuttings. The parameters measured were number of leaves, the percentage of rootng, root length, number of roots per rooted cutting and survival of rooted cuttings. Observations and data were made weekly during the experimental periods ( $4 \frac{1}{2}$ months) where cuttings, were carefully lifted for record and measurement of the parameters. The data were subjected to statistic analysis of variance by using JMP Software, discovered from SAS in 1989; Tuckey and kramer Test was used for mean separation.

\section{REsults}

Effect of hormone concentration: Analysis of variance results presented in Table 1 and 2 revealed significant $(p<0.001)$ effects of the growth regulator indole-3-butyric acid (IBA) on rooting percentage of stem cuttings obtained from mature Peltophorum petrocarpum trees. The highest rooting percent was obtained with IBA treatment at concentration of 200ppm which was significantly different from all other treatments (Table 1 and 2). The effect of IBA concentrations on means of root length and means of roots per cutting was found to be significantly different from 50 and $0.0 \mathrm{ppm}$ treatments. Treatment of 100ppm gave the taller root $(4.6 \mathrm{~cm})$ which was not significantly different from 200ppm $(4.3 \mathrm{~cm})$ as shown in Table 2. The rooted stem cuttings were transplanted in polythene bags $(20 \times 30 \mathrm{~cm})$; contain clay medium 
and watered every 2 days. Successful acclimatization of stem cuttings seedlings with 100\% and $96.6 \%$ survival rate was obtained with 100 and 200ppm IBA respectively.

Table 1 Effects of various IBA (Indole-3-butyric acid) concentrations on means of growth parameters of Peltophorum petrocarpum rooted stem cuttings after 6 weeks in November 2011

\begin{tabular}{|c|c|c|c|c|c|}
\hline $\begin{array}{c}\text { Treatment } \\
\text { IBA }(\mathrm{ppm})\end{array}$ & $\begin{array}{c}\text { Leaves No. } \\
\text { /cutting }\end{array}$ & $\begin{array}{c}\text { Root } \\
\text { No/cutting }\end{array}$ & $\begin{array}{c}\text { Length of } \\
\text { root }(\mathrm{cm})\end{array}$ & Root \% & Survival \% \\
\hline Control & $2 \mathrm{a}$ & $0 \mathrm{c}$ & $0.0 \mathrm{c}$ & $00.0 \mathrm{c}$ & 0 \\
\hline 50 & $3 \mathrm{a}$ & $6 \mathrm{ab}$ & $3.3 \mathrm{~b}$ & $40.0 \mathrm{~b}$ & 24 \\
\hline 100 & $2 \mathrm{a}$ & $9 \mathrm{a}$ & $2.3 \mathrm{~b}$ & $43.5 \mathrm{~b}$ & 75 \\
\hline 200 & $4 \mathrm{a}$ & $13 \mathrm{a}$ & $12.0 \mathrm{a}$ & $73.3 \mathrm{a}$ & 100 \\
\hline SE \pm & 0.06 & 1.1 & 2.3 & 10.0 & 7.45 \\
\hline Probability & 0.62 & 0.0004 & 0.02 & 0.007 & 0.001 \\
\hline
\end{tabular}

15 cuttings per replicate; In the same column, means followed by the same letter are not significantly different using JMP Test.

Table 2 Effects of various IBA (Indole-3-butyric acid) concentrations on means of growth parameters of Peltophorum petrocarpum rooted stem cuttings after 6 weeks in April 2012

\begin{tabular}{|c|c|c|c|c|c|}
\hline $\begin{array}{c}\text { Treatments } \\
\text { IBA }(\mathrm{ppm})\end{array}$ & $\begin{array}{c}\text { Leaves No. } \\
\text { /cutting }\end{array}$ & $\begin{array}{c}\text { Root } \\
\text { No/cutting }\end{array}$ & $\begin{array}{c}\text { Length of } \\
\text { root }(\mathrm{cm})\end{array}$ & $\begin{array}{l}\text { Root } \% \\
\%\end{array}$ \\
\hline Control & $0 \mathrm{c}$ & $0 \mathrm{c}$ & $0.0 \mathrm{c}$ & $00.0 \mathrm{c}$ & 0 \\
\hline 50 & $2.3 \mathrm{a}$ & $0 \mathrm{c}$ & $0.0 \mathrm{c}$ & $00.0 \mathrm{c}$ & 0 \\
\hline 100 & $3.7 \mathrm{a}$ & $5 \mathrm{a}$ & $4.6 \mathrm{a}$ & $36.7 \mathrm{~b}$ & 100 \\
\hline 200 & $3.3 \mathrm{a}$ & $8 \mathrm{a}$ & $4.3 \mathrm{a}$ & $56.7 \mathrm{a}$ & 96.6 \\
\hline SE \pm & 0.7 & 0.6 & 2.3 & 4.7 & 1.6 \\
\hline Probability & 0.02 & 0.0001 & 0.0001 & 0.0001 & 0.001 \\
\hline
\end{tabular}

15 cuttings per replicate; in the same column, means followed by the same letter are not significantly different using JMP Test

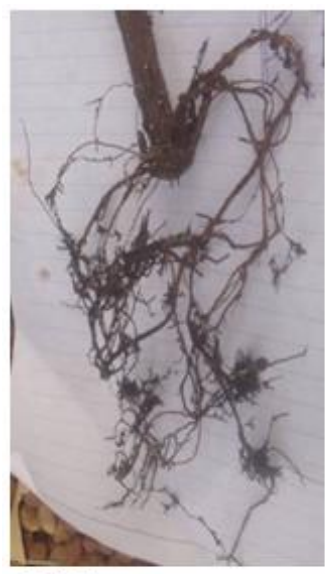

$200 \mathrm{ppm}$

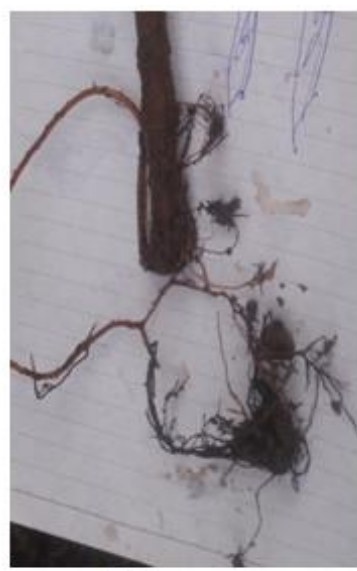

$100 \mathrm{ppm}$

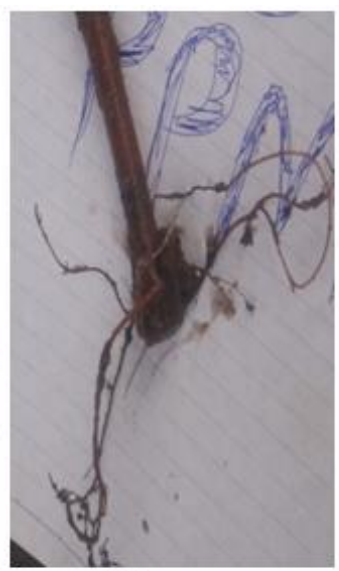

$50 \mathrm{ppm}$

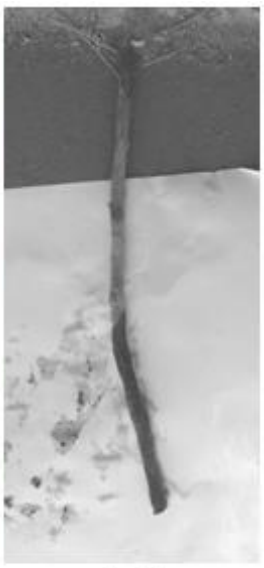

0.00

Fig 1: Effect of Indole -3- butyric acid (IBA) concentrations on growth performance of stem cuttings roots of Peltophorum petrocarpum 


\section{Discussion}

A successful propagation of mature plant of Peltophorum petrocarpum was attained by using the rooting hormone IBA (Indole-3-butyric acid). Vegetative propagation techniques were introduced in tree planting to overcome problems that prevent successful efficient propagation and production of socioeconomic forest tree species. Moreover the techniques practiced will put answers of how to determine and control appropriate physiological conditions of propagated plant materials. Treated and untreated stem cuttings with exogenous treatment with IBA exhibited periodic variations in rooting responses, where it enhances rooting. From the experiment it seems that persistence of physiologically active leaves and development of buds into branches are prominent signs of rooting of cuttings. Also it seems that rooting percentage affected by IBA treatments at various concentrations due to their different responses on rooted cuttings. Similarly Jones et al. (1990) work on a number of Acacia species showed the same phenomena.

The effectiveness of auxins for root formation may also be related to changes in the levels of contents of internal nutrients such as phenols and carbohydrates compounds in stem cuttings. These were supported by the work of Ali (1986) on some forest trees. It seems that the initiation of rooting could be due to influences by auxins interaction with chemicals, growth cofactors or auxins synergists of phenol compounds and high concentrations of cytokinins.

The low percentage of rooted cuttings indicated slow down of growth in shoots, and probably could be due to low rootability and interactions of other unforeseen cofactors. In addition to suggested links that existed between phytohormones, whereas several hormones modulate or are modulated by auxins levels and responses ((Eklöf et al., 2000); and auxins treatments can rapidly inhibit cytokines biosynthesis (Nordström et al., 2004). Similarly Zobel, and Talbert (1984) related the rooting ability of stem cuttings to morphological status of the parent tree and these variations presumably attributed to the hormonal contents of the shoots from which the cuttings were obtained. Therefore it could be assumed that the formation of adventitious roots are initiated or affected by other factor that interacts with hormone translocation from the shoot. The conclusion reached is that rooted cuttings can be used successfully for obtaining health, free-disease and uniform plantations of $P$. petrocarpum for mass production and large-scale tree planting activities.

\section{REFERENCES}

Ali, Y. A. 1986.Vegetative Propagation of some Forest Trees::Structural;

Ali, Y.H., and El-Tigani, S. (2003). Vegetative Propagation of Acacia senegal (Willd.) by Stem Cuttings. Sudan Silva 9 (2): 36-45.

Badji, S., Ndiaye, I., Danthu, P. and Colonna, J.P. (1991). Vegetative propagation studies on gum arabic trees.1- propagation of $A$. senegal $(L)$ Wild. using lignified cuttings of small diameters with eight nodes. Agroforestry Systems. 14:183-191.

Eklöf S, Åstot C, Sitbon F, Moritz T, Olsson O, Sandberg G. 2000. Transgenic tobacco plants coexpressing Agrobacterium iaa and ipt genes have wild-type hormone levels but display both auxin- and cytokinin-overproducing phenotypes. Plant Journal 23: 279-284.

El El-Amin, H. M. 1990. Trees and Shrubs of the Sudan. Ithaca Press Exeter. Pp 217.

Hartman, H. T. and Kester, D. E. 1983. Plant propagation: Principles and

Hussey, G. 1986. Propagation, plant breeding and the conservation of germplasm. In: Plant cell culture techniques. Edited by M. .M. Yeoman. Blackwell Scientific Publication, Oxford, England. pp. 29-58.

Koh, H. L., T. K. Chua \& C. H. Tan, 2009. A Guide to Medicinal Plants: An Illustrated, Scientific and Medicinal Approach. World Scientific Publishing, Singapore. 292 pp.

Libby, W. J. And Rauter, R. M. 1984. Advantages of Clone Forestry. Scientific and Technical Articles. The Forestry Chronicle 145-149 
Longman, K. A., and Jenik, J. J. 1990. Tropical Forest and its Environment ( $2^{\text {nd }}$ ed.) Co-Published in the United States with John Wiley and sons Inc., New York.

Nordström A, Tarkowski P, Tarkowska D, Norbaek R, Åstot C, Dolezal K, Sandberg G. 2004. Auxins regulation of cytokinins biosynthesis in Arabidopsis thaliana: a factor of potential importance for auxins-cytokinins regulated development. Proceedings of the National Academy of Science of the USA 101: 8039-8044.

Physiological and Biochemical Aspects. M Sc. thesis University of Khartoum. Sudan. practices $\left(4^{\text {th }}\right.$ Ed.) Prentice Hall. Inc. New Jersey. 662pp.

studies for tropical improvement and conservation.: Factors affecting root initiation in cuttings of Triplochiton scleroxylon. K. Scham. Forest Ecology and Management. 4: 53-66.

T.C. Jones, C.A. Batchelor and P.J.C. Harris 1990. In vitro culture and propagation of Acacia species (A. bivenosa, A. holosericea, A. salicina, A. saligna and A. sclerosperma). Intl. Tree Crops J. 6: 183-192.

Tigani, S. 2003. Comparative Anatomy of Stem Explants Used in Vegetative Propagation of some Acacia species. Sudan Journal of Basic Sciences. Series B: Biological Science: 9-21. Publisher Sudan Institute for Natural Sciences

Wee, Y. C. 2003. Tropical trees and shrub. A selection for urban plantings. Sun Tree Pub., Singapore. 392pp.

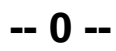

